\title{
THE EFFECTS OF WITHDRAWAL AND MELT OVERHEATING HISTORIES ON THE MICROSTRUCTURE OF A NICKED-BASED SINGLE CRYSTAL SUPERALLOY
}

\author{
Lin Liu, Taiwen Hang, Minming Zou, Weiguo Zhang, Jun Zhang, Hengzhi Fu \\ State Key Laboratory of Solidification Processing, Northwestern Polytechnical University, \\ Xi'an 710072, PR of China
}

Keywords: Directional solidification, Melt overheating, Withdrawal velocity, Dendritic spacing, Superalloy.

\begin{abstract}
The solidification interface morphologies of a single crystal superalloy DD3 have been studied over a range of cooling rate with large variations in withdrawal speeds in high-thermal gradient directional solidification. The effect of withdrawal and thermal histories on the dendrite morphologies and spacing is also studied. The results show that increasing either thermal gradient or withdrawal rate will refine the dendrite. Especially, super-fine dendrite structure with suppressed side branches was found under the cooling rate as high as $10 \mathrm{~K} / \mathrm{s}$ during high thermal gradient directional solidification. The initial withdrawal histories and melt superheat treatment on dendrite morphologies are significant: with the increase in the initial acceleration withdrawal speed, the primary dendrite arm spacing in stable growth zone decreases. By growth velocity transition from higher one to lower one abruptly, the primary dendrite spacing, and constitutional segregation in the stable growth zone can be reduced and vice versa. Melt superheating treatment prior to solidification can stabilize liquid/solid interface and refine primary dendrite and $\gamma^{\prime}$ phase obviously. Whereas, the secondary dendrite arms seem not sensitive neither to melt superheating treatment, nor initial acceleration withdrawing.
\end{abstract}

\section{Introduction}

It becomes a common process of turbine blades by investment casting of the superalloys, very often into single-crystal form. Bridgman high rate solidification technique (HRS), consequently, is a predominant manufacture process of single crystal blades. During directional solidification, thermal gradient $(G)$ and growth velocity $(V)$ influence the scale of dendrite structure which can be characterized by their microstructure parameters, such as primary dendrite arm spacing $\left(\lambda_{1}\right)$, secondary dendrite arm spacing $\left(\lambda_{2}\right)$, dendrite tip radius $(r)$ and mushy zone depth $(d)$. Numerous studies [1-4] have been reported with the aim to characterize these parameters as a function of growth rate and thermal gradient ahead of the microscopic solidification front during directional solidification for nickel-base superalloys.

It must be pointed that the dendrite spacings depend not only on thermal gradient and on growth rate, but also on the history of the specimen [5-9]. This has been interpreted in such a way that no unique spacing selection criterion operates for $\lambda_{1}$ and an array with a band of the spacings is stable under given experimental conditions. The value of $\lambda_{1}$ is different with the same final experimental parameters if the solidification processes underwent the various initial processes, indicating that the characteristic scale is history-dependent. Unfortunately current experimental and theoretical works are seldom involving developing history during directional solidification for superalloys, even that history process to influence the resulting morphologies is not clear.

The cast microstructure of superalloys also depends on thermal history of the melt. The present author studied the melt superheating on the cast structure of In738 superalloy [10]. Yin et al [11] investigated the effect of melt superheat histories on the grain size and MC carbide morphologies of superalloys M963. No report was found with regards to the relationship between dendrite characteristics and melt treatment histories for single crystal superalloys. The morphology evolution of liquid/solid interface during solidification is mostly important in solidification process researching. Unfortunately, little literature has been found for the morphology evolution of L/S interface regarding melt structure.

The aim of present presentation is to establish the relationship between microstructure features and solidification parameters of single crystal superalloys under high thermal gradient directional solidification. The effects of withdrawal and thermal overheating histories on the dendrite structure and spacing are also addressed, respectively.

\section{Experimental}

A first-generation nickel-based single crystal superalloy DD3 (9.5 wt.\% Cr, 5.2W, 5Co, 4.2Mo, 5.7 Al, 2.3Ti, 0.006 $\mathrm{C}$ and $\mathrm{Ni}$ as balance) was used.

The phase and structural transformation temperatures of the alloy were studied by differential thermal analysis by using STA NETZSCH 409CD Thermal Analyzer. Figure 1 shows the results of DD3 alloy with calefactive rate $20^{\circ} \mathrm{C} / \mathrm{min}$. The liquidus temperature is indicated to be $1382.4^{\circ} \mathrm{C}$. At the range of $1382.4-1650^{\circ} \mathrm{C}$, there are a series of endothermic or exothermic kurtosis in DTA curves which imply occurring of several structural transformations in the liquid. According to the previous research [12], the peak happening at $1408.9^{\circ} \mathrm{C}$ should be the dissolution of MC-type carbides. The meaning of other peaks at higher temperature is still not clear. 


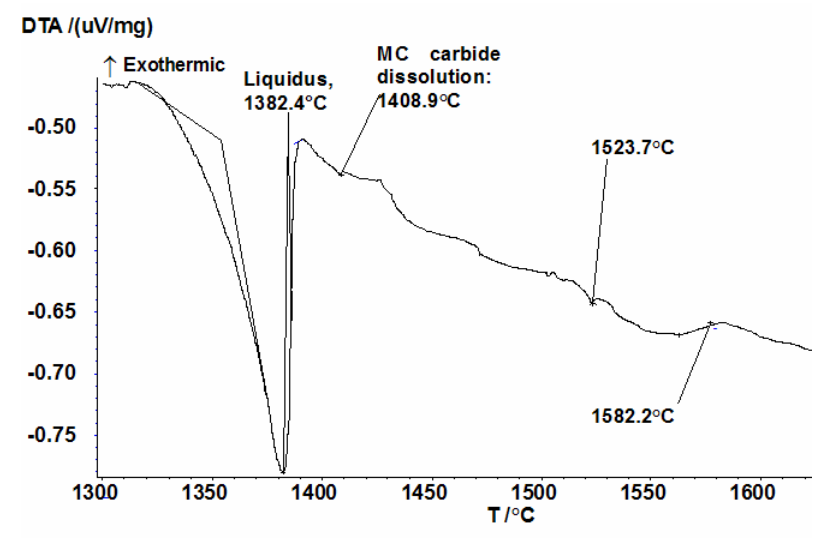

Figure1 Differential thermal analysis curve of DD3 alloy

The alloy was directionally solidified with a Bridgman-type high thermal gradient apparatus developed in the author's laboratory. A zone intensified overheating together with liquid metal cooling method was used to obtain higher thermal gradient. As shown in Figure 2, the alloy is melted by a primary heater and overheated again to higher temperature by an intensified heater placed at the vicinity of liquid/solid interface. Details of the experimental equipment are described elsewhere [13].

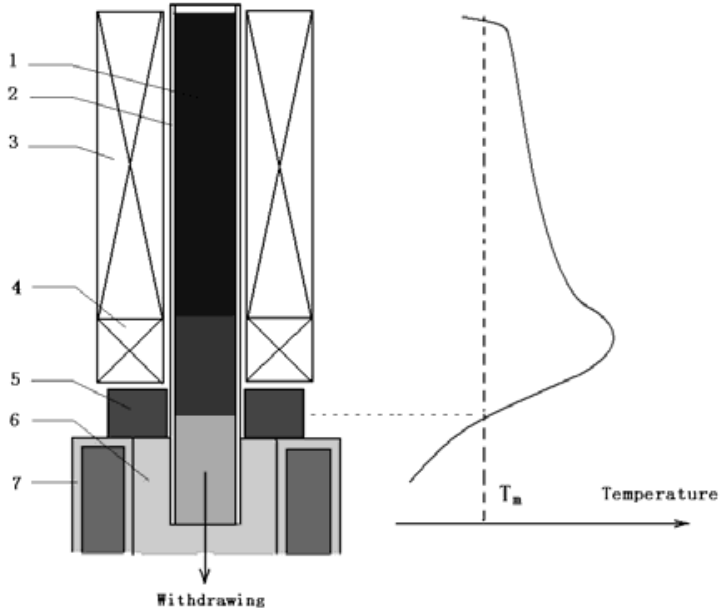

Figure 2 Zone intensified overheating \& liquid metal cooling (ZIOLMC) directional solidification and obtained temperature profile

1-sample, 2-ceramic crucible, 3-primary heater, 4-intensified heater, 5-thermal baffle, 6- low melting liquid metal (coolant), 7- water cooling jacket.

Samples with $7 \mathrm{~mm}$ in diameter and $115 \mathrm{~mm}$ in length were prepared. By using a computer controlled withdrawal system, various withdrawal rates, ranging from $0.1 \mu \mathrm{m} / \mathrm{s}$ to $900 \mu \mathrm{m} / \mathrm{s}$, were obtained. The thermal gradient at the solidification front measured using B-type thermocouples was from 200 to $800^{\circ} \mathrm{C} / \mathrm{cm}$. Single crystal was prepared by the bottom seeding technique.

The directionally solidified microstructure was obtained via four different ways: withdraw the samples at a predetermined rates to study the effect of the growth rates, withdraw the samples under different initial withdrawal histories in which various acceleration values were taken before reaching to stable growth velocity $\left(V_{s}\right)$, withdraw the samples at a changing rates abruptly from one growth rate to another, and superheat the melt to a predetermined temperature above the liquidus of the alloy and holding a period and then solidify the samples.

Withdrawal velocity curves can be controlled by the frequency adjustment of the servo system's input instruction. Apart from the normal withdraw, we set both additional withdrawal modes: start from zero and gradually accelerate to the constant speed (curve I in Figure 3), or change speed abruptly from one to another (curve II and III). In the first mode, after the various initial non-stable processes, the specimen then grew no less $20 \mathrm{~mm}$ to establish the same steady state conditions. In the second manner, steady growth must be achieved in both steps.

During the melt superheating process (see Figure 4), the melt was first heated to the temperature $T_{S}$, holding a period of $\left(t_{2}-t_{1}\right)$, then cooled to temperature $T_{0}$, and then solidified. The effect of thermal histories, including superheating temperature $T_{s}$ and homogenisation time $\left(t_{2}-t_{1}\right)$, on the solidification structure were examined.

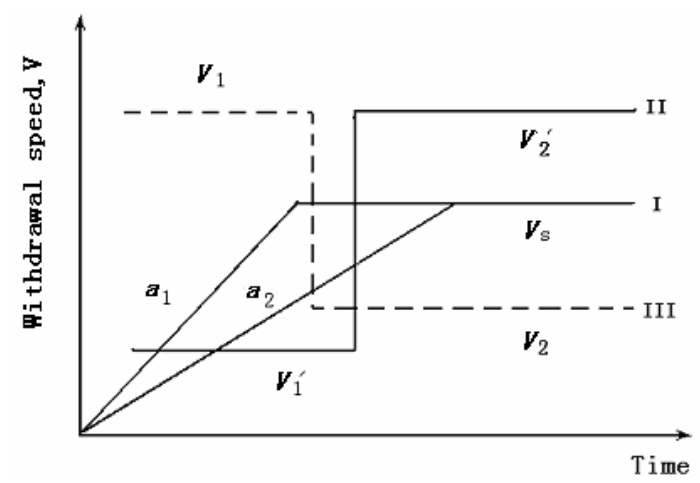

Figure 3 The initial withdrawal histories: I. Gradual-shift seeding mode with different acceleration; II. Transition from low velocity stable growth to high velocity stable growth; III. Transition from high velocity stable growth to low velocity stable growth

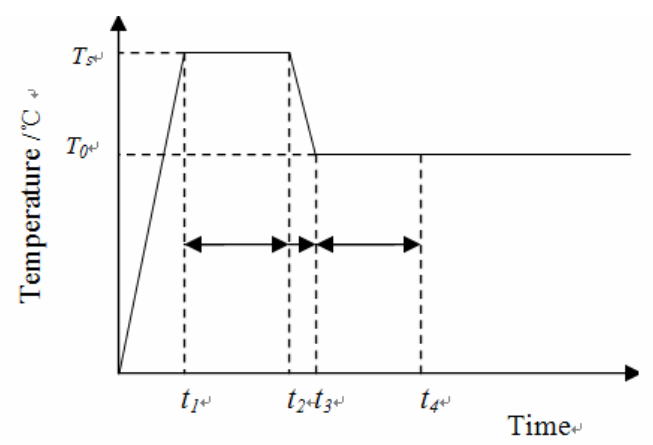

Figure 4 The thermal histories by superheating the melt

Microstructures of all samples were examined using optical and electron microscopy. Quantitative analyzing of the 
microstructures was performed by image analyzer. The concentrations of main alloying elements of $\mathrm{Al}, \mathrm{Ti}$, Ta and $\mathrm{W}$ in interdendritic areas and in dendrite core were analyzed by electron microprobe. The cooling rates during directional solidification were determined from primary dendrite spacing according to Mehrabian's equation [14].

\section{Results and Discussions}

\section{$\underline{\text { Solidification Morphologies under Constant Growth Rates }}$}

Figure 5 shows the dendrite morphologies under different withdrawal rates and thermal gradients. At higher withdrawal rates, dendrite is continually refined; those characteristics can be represented as suppressed side branches and shortened primary and secondary spacings. Increase in thermal gradient affects the dendrite morphology in the same way as the withdrawal rate: the dendrite is refined at higher thermal gradient under identical withdrawal rate, see Figure 5 (c) and (d).
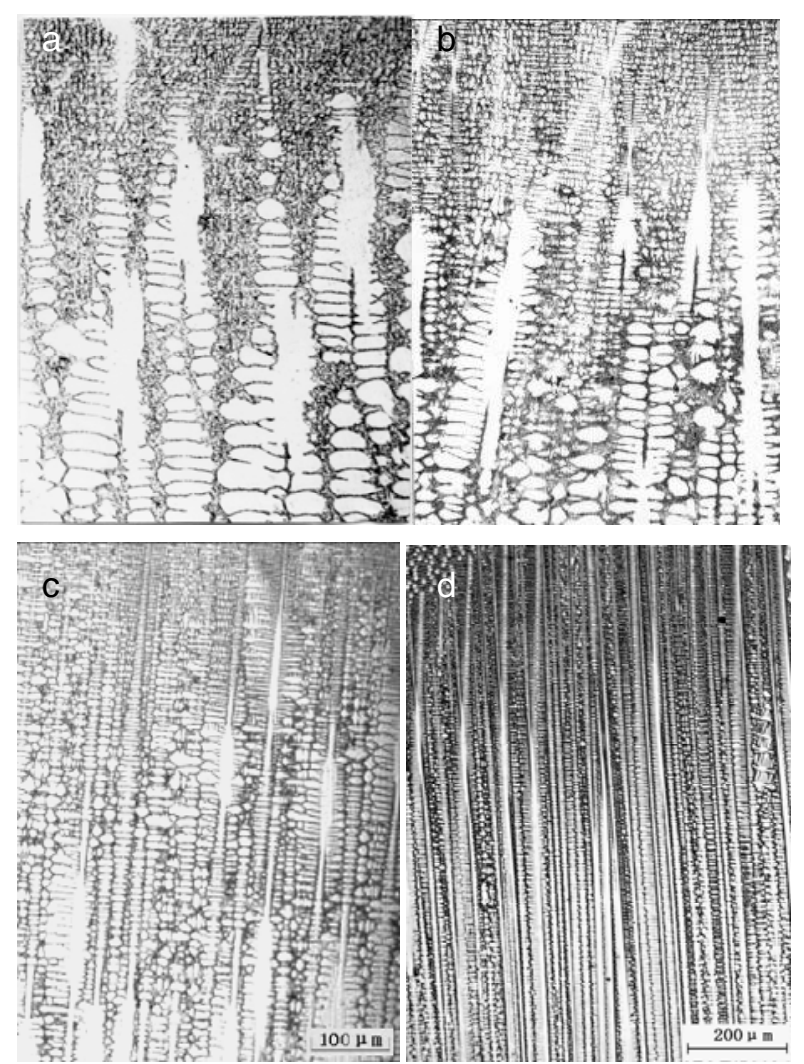

Figure 5 Growth morphologies under various withdrawal rates and thermal gradients

(a) Coarse dendrite, $\mathrm{V}=6.67 \mu \mathrm{m} / \mathrm{s}, \mathrm{G}=200 \mathrm{~K} / \mathrm{cm}$;

(b) Coarse dendrite, $\mathrm{V}=13.3 \mu \mathrm{m} / \mathrm{s}, \mathrm{G}=200 \mathrm{~K} / \mathrm{cm}$;

(e) Fine dendrite, $\mathrm{V}=100 \mu \mathrm{m} / \mathrm{s}, \mathrm{G}=200 \mathrm{~K} / \mathrm{cm}$;

(d) Super-fine dendrite, $\mathrm{V}=100 \mu \mathrm{m} / \mathrm{s}, \mathrm{G}=800 \mathrm{~K} / \mathrm{cm}$.

In order to characterize dendrite morphology quantitatively, we measured the primary and secondary dendrite arm spacings, which are indicated with $\lambda_{1}$ and $\lambda_{2}$, respectively. The results are shown in Table 1. It can be seen that they are refined extensively with increasing cooling rate $\dot{T}$, which can be defined as $G \cdot R$, where $\mathrm{R}$ is growth rate.

The growth rate is equivalent to withdrawal rate in most circumstances. Accordingly, we can calculate the cooling rate by using withdrawal rate instead of growth rate without noticeable error. Referring to Figure 5, we can see that side branches begin to be suppressed at the cooling rate of $2 \mathrm{~K} / \mathrm{sec}$. The fine structure can be found when the cooling rate reaches $10 \mathrm{~K} / \mathrm{sec}$. Its spacing is $38 \mu \mathrm{m}$ in this case, reduced by a factor of about $7-10$ as compared with the conventional high rate solidification (HRS) process in which typical thermal gradient is below $60 \mathrm{~K} / \mathrm{cm}$.

Table 1 Dendrite arm spacing under different cooling rates

\begin{tabular}{|l|l|l|l|l|l|l|}
\hline $\begin{array}{c}\dot{T}, \\
\mathrm{~K} / \mathrm{sec}\end{array}$ & 0.11 & 0.13 & 0.27 & 1.00 & 2.00 & 10 \\
\hline $\begin{array}{c}\lambda_{1}, \\
\mu \mathrm{m}\end{array}$ & 245 & 154 & 123 & 85 & 79 & 38 \\
\hline $\begin{array}{l}\lambda_{2}, \\
\mu \mathrm{m}\end{array}$ & 40 & 35 & 29 & 26 & 18 & N.D. \\
\hline
\end{tabular}

\section{The Effect of Initial Withdrawal Histories}

The Effect of Gradual-Shift Seeding Mode According to the constitutional undercooling theory, high thermal gradient can effectively suppress the formation of equiaxed grains ahead of solidification interface, and therefore permits maintaining directional structure under fast growth rate. On this basis, we can effectively increase growth velocity since the production of the DS superalloy components is always time-consuming. However, the processing to produce single-crystal superalloys at high growth rates, normally larger than $300 \mu \mathrm{m} / \mathrm{s}$, by bottom seeding technique brings us new problems. Owing to the hysteresis of interface growth velocity responding to imposed withdrawing velocity at initial interval, mushy zone can be moved down and pulled out of the adiabatic zone in the furnace, thus producing non-negligible transverse thermal gradients. The departure distance of $\mathrm{L} / \mathrm{S}$ interface from nominal stable position is maximal at a transient-shift seeding, and increases with higher growth velocities. Under some conditions $(V>300 \mu \mathrm{m} / \mathrm{s})$, these transient-shift seeding modes may result in a bending $\mathrm{L} / \mathrm{S}$ interface at initial growth periods and consequently a failure of seeding or primary dendrite toward the centerline of the samples, see Figure 6(a). It is probably an effective way to improve seeding quality by gradual-shift seeding mode, that is to use an accelerated withdrawal mode at the initial period. In this seeding mode, the initial departure distance of interface is reduced and the growth interface changes to a flat plane, thus causes dendrites well aligned with the withdrawal direction (Figure 6 (b)). It must be mentioned that for different directional solidification systems and interface positions at adiabatic zone, the initial behavior may be different.

Although a gradual-shift seeding mode contributes to wellcontrolled directional solidification microstructure, the imprint of initial histories on subsequent stable-growth microstructure must be taken into account. Table 2 shows the processing parameters and microstructural characteristics given by different initial withdrawal histories. The microstructure in the stable growth zone can be seen in Figure 7. The experimental results indicate that the initial processing considerably influences the microstructure given by stable growth. The higher the initial acceleration value, the smaller the primary dendrite arm spacing 
is. In contrast, the secondary dendrite arm spacing evidently does not change with initial processing.
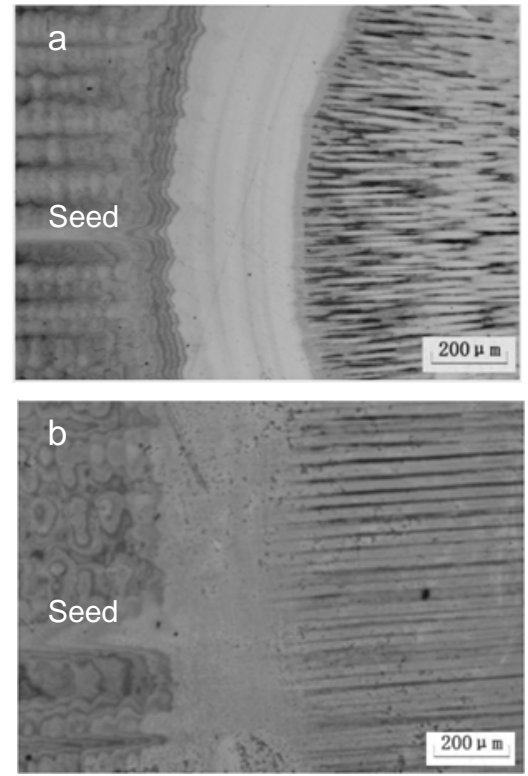

Figure 6 The effect of initial seeding modes on L/S interface shape, growth direction is from the left to the right.

(a) $V_{s}=500 \mu \mathrm{m} / \mathrm{s}$, Transient-shift seeding;

(b) $V_{s}=500 \mu \mathrm{m} / \mathrm{s}$, Gradual-shift seeding, $a=50 \mu \mathrm{m} / \mathrm{s}^{2}$.

Table 2 The effect of initial withdrawal parameters on microstructure at steady state

\begin{tabular}{|c|c|c|c|c|}
\hline $\begin{array}{c}\text { Frequency } \\
\text { alteration } \\
\text { mode }\end{array}$ & $\begin{array}{c}\text { Acceleration } \\
\left(\mu \mathrm{m} / \mathrm{s}^{2}\right)\end{array}$ & $\begin{array}{c}\text { Withdrawal } \\
\text { rate }(\mu \mathrm{m} / \mathrm{s})\end{array}$ & $\lambda_{1}(\mu \mathrm{m})$ & $\lambda_{2}(\mu \mathrm{m})$ \\
\hline $2 \mathrm{~Hz} / 57 \mathrm{~ms}$ & 10 & 900 & 106.7 & 14.7 \\
\hline $10 \mathrm{~Hz} / 57 \mathrm{~ms}$ & 50 & 900 & 53 & 14.3 \\
\hline
\end{tabular}
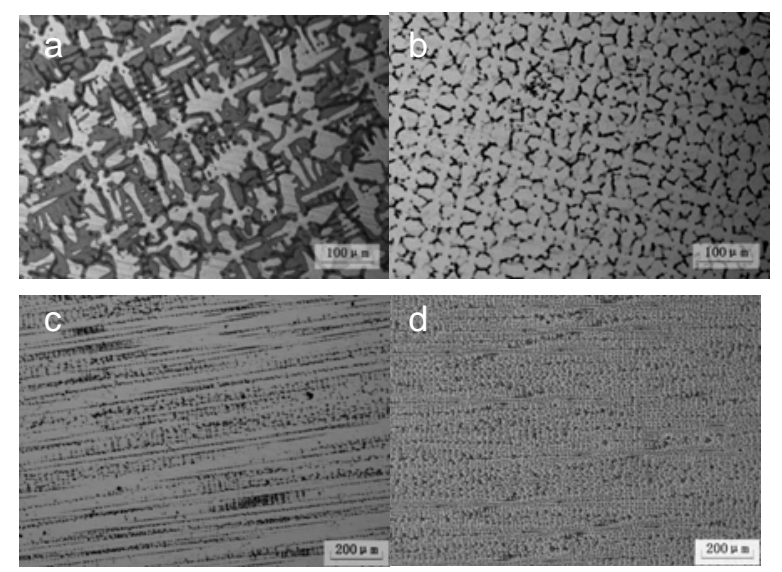

Figure 7 The dendrite morphologies at different initial withdrawal histories.
(a), (c) $V=900 \mu \mathrm{m} / \mathrm{s}, a=50 \mu \mathrm{m} / \mathrm{s}^{2}$;

(b), (d) $V=900 \mu \mathrm{m} / \mathrm{s}, a=10 \mu \mathrm{m} / \mathrm{s}^{2}$.
The experimental results reveal that the control of the growth histories of superalloys may become an effective way to achieve a perfect microstructure of single-crystal preparation of superalloys.

The primary dendrite arm spacing can adjust in response to changing conditions by different mechanisms. These adjustment mechanisms include dendrite elimination, dendrite tip splitting and the growth of tertiary arms [15]. The $\lambda_{1}$ value can be augmented by dendrite elimination and reduced by dendrite tip splitting and growth of tertiary arms. When a dendrite tip splits or a tertiary arm overgrows, additional interface is produced and a certain amount of undercooling is needed to overcome energy barrier for spontaneous growth. Those phenomena may happen in the transition zone where growth occurs under different acceleration conditions. This may give rise to the history dependence of primary dendrite arm spacing. Furthermore, different acceleration values can induce different undercooling kinetics which will influence non-stable evolution from a coarse array to a finer one.

Langer and Müller-Krumbhaar [16] have carried out a detailed numerical analysis of the wavelength of instabilities along the sides of a dendrite and have predicted the scaling law as $\lambda_{2} / r=$ 2 , where $r$ is dendrite tip radius. Since the dendrite tip radius is controlled by temporal conditions, as acknowledged in the models of Kurz-Fisher [17] that $r$ is a function of $V$ and $C_{0}$. The secondary dendrite arm spacing is therefore not history dependent.

The Effect of Abrupt Growth Velocity Transition The effect of histories of DS process on subsequent microstructure is essentially the fact that the preformatted dendrite will regulate the formation of succeeding dendrite during continuous growth. A transition which begins with a given microstructure will be more important to study the histories-relevant morphology evolution. Accordingly, experiments of DS process from one certain stable condition changing to another condition have been carried out, and the results are shown in Figure 8. The final primary dendrite spacing will be shortened if it underwent lower growth rate but be enlarged if it underwent higher growth rate. Table 3 indicates that the final primary dendrite arm spacings (PDAS's) are affected greatly by the preformatted ones. For example, the PDAS is $71 \mu \mathrm{m}$ at normal condition and increases to $93 \mu \mathrm{m}$ if the preformatted growth rate is $100 \mu \mathrm{m} / \mathrm{s}$. On the contrary, the reduced succeeding spacings are found if they underwent the higher growth rate at which PDAS is much smaller.

In practical solidification processes, there are inevitable fluctuations in the processing conditions, which may affect the dendrite growth and thereby change the final dendritic spacing. This may be the cause of no unique primary cellular/dendritic spacing, but rather a range of spacing for a given processing condition in many experimental results.

For a given final processing condition, there are one upper and lower limits of the allowable primary dendrite spacing. Hunt and $\mathrm{Lu}[18]$ predicted by using a quasi-3D simulation that the upper limit of the $\lambda_{I}$ distribution is about two times as the lower limit, whereas Wang [19] suggested a factor of approximately three. In the present work, the results show that the maximum value of the $\lambda_{1}$ distribution under $100 \mu \mathrm{m} / \mathrm{s}$ growth rate is nearly three times as that of the minimum value, as seen in column 3 in Table 3. 

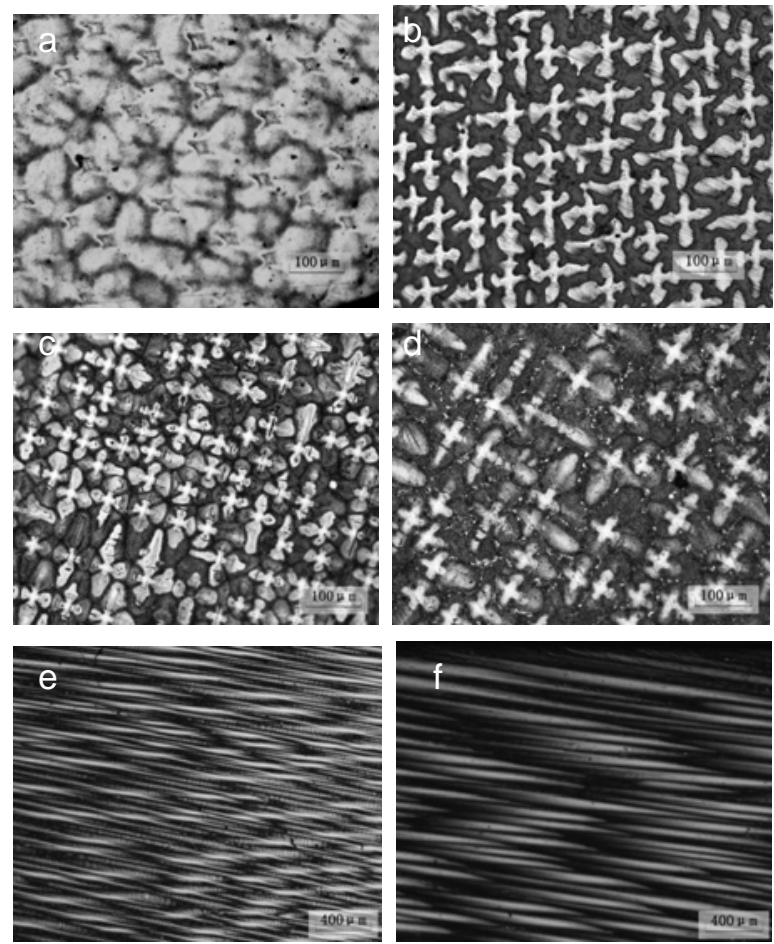

Figure 8 the effect of growth velocity transition on dendrite morphology

(a), (b): growth velocity transition from $100 \mu \mathrm{m} / \mathrm{s}$ to $300 \mu \mathrm{m} / \mathrm{s}$

(c), (d): growth velocity transition from $300 \mu \mathrm{m} / \mathrm{s}$ to $100 \mu \mathrm{m} / \mathrm{s}$

(e), (f): growth velocity transition from $600 \mu \mathrm{m} / \mathrm{s}$ to $20 \mu \mathrm{m} / \mathrm{s}$

Table 3 The primary dendrite arm spacings $(\mu \mathrm{m})$ at the steady state when growth rate transits from $V_{1}$ to $V_{2}$

\begin{tabular}{|c|c|c|c|c|}
\hline$V_{1}, \mu \mathrm{m} / \mathrm{s}$ & \multicolumn{4}{|c|}{$V_{2}, \mu \mathrm{m} / \mathrm{s}$} \\
\cline { 2 - 5 } & 20 & 100 & 300 & 600 \\
\hline 0 & 212 & 145 & 71 & 48 \\
\hline 100 & $/$ & $/$ & 93 & $/$ \\
\hline 300 & 92 & 86 & $/$ & $/$ \\
\hline 600 & $/$ & 62 & $/$ & $/$ \\
\hline
\end{tabular}

The secondary dendrite arm has been modulated by different PDAS. When the growth velocity changes from $600 \mu \mathrm{m} / \mathrm{s}$ to $20 \mu \mathrm{m} / \mathrm{s}$, even a kind of especial microstructure with no visible second dendrite arm has been found, as seen Figure 8 (e), (f). Therefore, the constitutional distribution will be altered by growth rate transition. As seen in Figure 9, the constitutional segregation of these samples produced by rate transition from $600 \mu \mathrm{m} / \mathrm{s}$ to $20 \mu \mathrm{m} / \mathrm{s}$ is significantly less than that of sampled produced at the constant rate of $20 \mu \mathrm{m} / \mathrm{s}$. The segregation ratio (SR), which is defined as the maximum concentration in interdendrite areas over the minimum concentration in the dendrite core, will reduce during the transition. The results indicate that the previous growth velocity histories influence on the final microstructure features obviously.

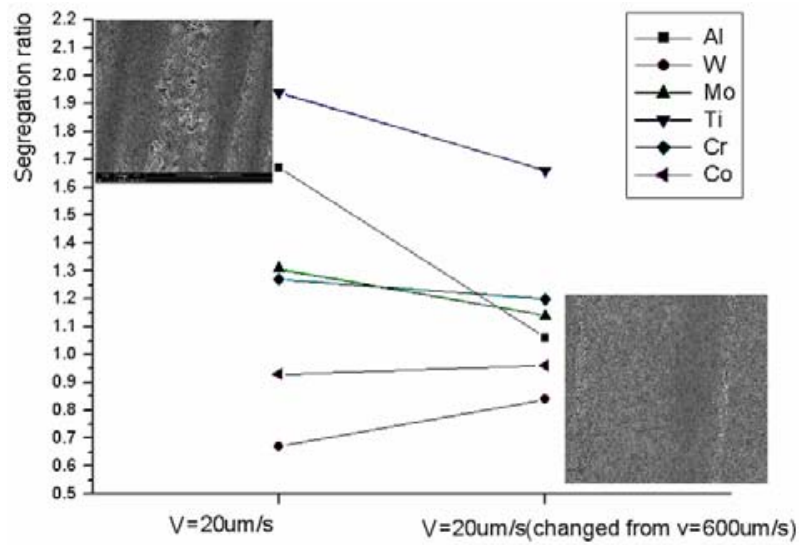

Figure 9 The effect of growth velocity transition on the constitutional segregation and the morphology of $\gamma-\gamma^{6}$

Thus, a proper transition in the process parameters early in the formation of the dendritic microstructure might result in an improved product.

\section{The Effect of Melt Superheating Treatment}

Figure 10 shows the effects of different melt overheating temperatures on the morphology of $\mathrm{S} / \mathrm{L}$ interface. The original interface morphologies are planar and cellular-dendrite at the growth velocity of $1.0 \mu \mathrm{m} / \mathrm{s}$ and $5.0 \mu \mathrm{m} / \mathrm{s}$, respectively. After higher melt superheating treatment at $1780^{\circ} \mathrm{C}$, the cellular interface is smoothened to planar and the side branches in cellular-dendrite structure disappear at different growth velocities, indicating that melt superheating treatment will stabilize the L/S interface during directional solidification.
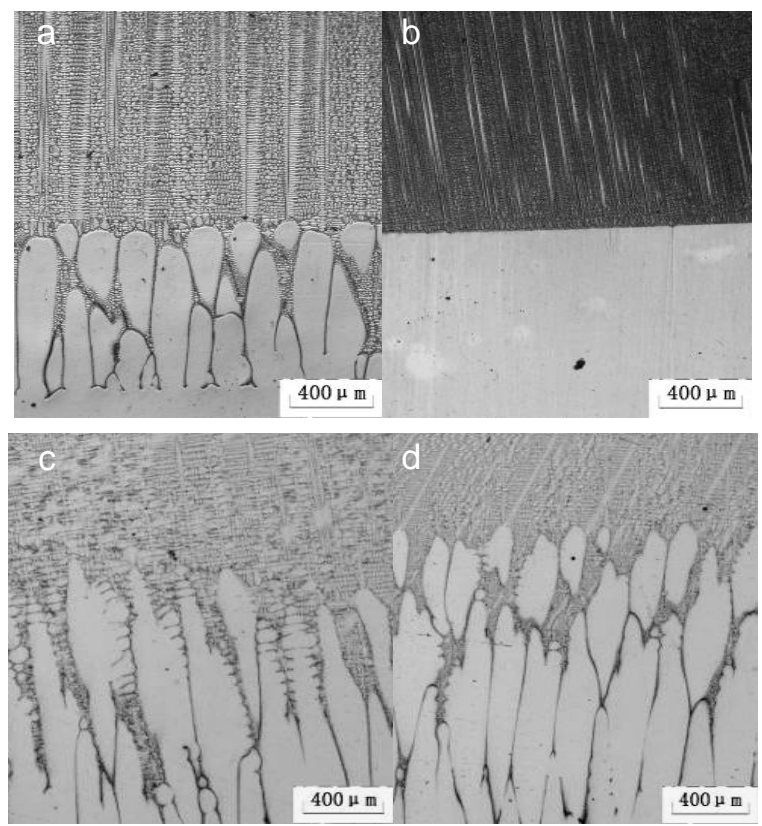

Figure 10 Morphology of $\mathrm{S} / \mathrm{L}$ interface under different melt overheating temperatures

(a), (c) $t_{\mathrm{S}}=t_{0}=1500^{\circ} \mathrm{C}$, (b), (d) $t_{\mathrm{S}}=1780^{\circ} \mathrm{C}$;

(a), (b) $V=1.0 \mu \mathrm{m} / \mathrm{s}$, (c), (d) $V=5.0 \mu \mathrm{m} / \mathrm{s}$. 
The micrographs of transverse section of samples in Figure 11 show the primary dendrite arms at different melt superheating temperature. It is clearly seen that the dendrite structure is refined with the increase of melt superheating temperature. Figure 12 reveals that the primary dendrite arm spacing decreases at higher melt superheating temperature at any growth rate.

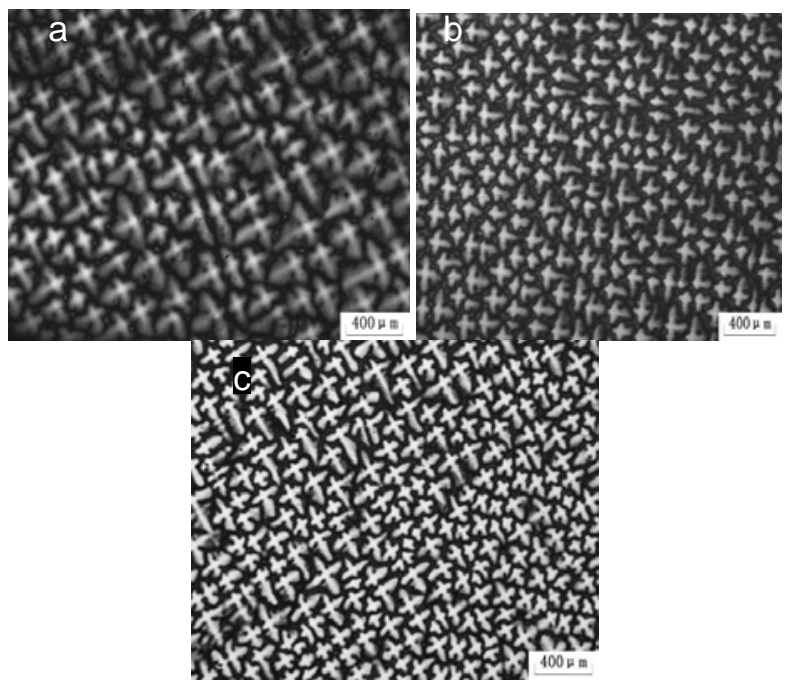

Figure 11 The dendrite morphologies at different melt superheating temperatures, $\mathrm{V}=20 \mu \mathrm{m} / \mathrm{s}$.

(a) $T_{\mathrm{S}}=T_{0}=1500^{\circ} \mathrm{C}$, (b) $T_{\mathrm{S}}=1640^{\circ} \mathrm{C}$, (c) $T_{\mathrm{S}}=1780^{\circ} \mathrm{C}$.

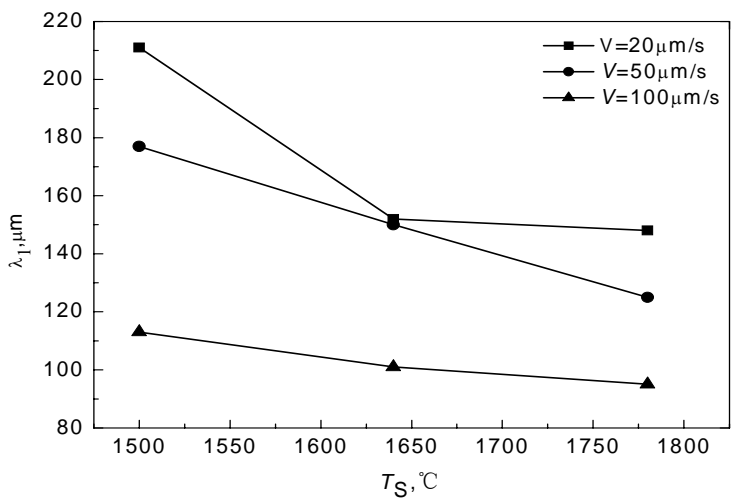

Figure 12 Primary dendrite spacing under different melt superheating temperature

The size of $\gamma^{\prime}$ particles in both dendrite core and interdendritic areas decrease with the increase of melt superheating temperature from $1500{ }^{\circ} \mathrm{C}$ to $1640{ }^{\circ} \mathrm{C}$ and then to $1780{ }^{\circ} \mathrm{C}$. Furthermore, the morphology of $\gamma^{\prime}$ particles in interdendritic area become more uniform, as shown in Figure13.

Since all structure features are refined after melt superheating treatment, it is expected that the mechanical properties will be improved for refined structure.

The experiment results show that the change of dendrite morphologies, size of $\gamma^{\prime}$ strengthening precipitates and microsegregation of the elements is favorable under different withdrawal and melt thermal histories, indicating that those methods are effective ways to control microstructure of single crystal superalloys.
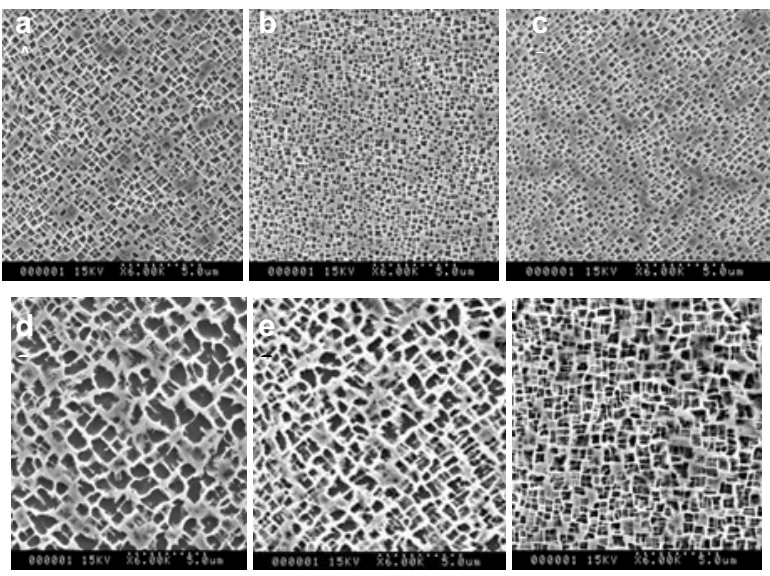

Figure 13 Morphology of $\gamma^{\prime}$ particles under different melt overheating temperatures.

(a), (d) $T_{\mathrm{S}}=T_{0}=1500^{\circ} \mathrm{C}$; (b), (e) $T_{\mathrm{S}}=1640^{\circ} \mathrm{C}$; (c), (f) $T_{\mathrm{S}}=1780^{\circ} \mathrm{C}$; (a), (b), (c) dendritic area (d), (e), (f) interdendritic area.

The mechanism of melt superheating is related to the alternation of physical or chemical properties of the melt, such as diffusive coefficient, viscosity or partition coefficient, and even to the change of liquid structure. It has been found by some investigations [20] that the melt structure of Ni-based superalloy changes from order to disorder with melt temperature increase. There exist $\mathrm{Ni}_{3}(\mathrm{Al}, \mathrm{Ti}, \mathrm{Nb})$-like cluster, $\mathrm{MC}$ carbide cluster and other high-melting particle in the melt when the melt temperature is lightly higher than the liquidus. The present author [10] found that MC carbide will not completely dissolve below $1495{ }^{\circ} \mathrm{C}$. With the melt temperature increase, the $\mathrm{Ni}_{3} \mathrm{Al}-$ liked and $\mathrm{MC}$ carbide cluster will decrease in their sizes below $1600{ }^{\circ} \mathrm{C}$ and even disappear in the alloy melt above $1600{ }^{\circ} \mathrm{C}[20]$, which may lead to obvious increase in the melt undercooling degree and the melt uniformity.

All these factors will influence the solidification microstructures Due to their uncertainty and complexity, setting up relationship between microstructure feature and alloy melt characteristics still needs to study.

\section{Conclusions}

(1) Increasing either thermal gradient or withdrawal rate will refine the dendrite. Especially, super-fine dendrite structure with suppressed side branches was found under the cooling rate as high as $10 \mathrm{~K} / \mathrm{s}$ during high thermal directional solidification.

(2) The effects of initial withdrawal histories on dendrite morphologies are significant. With increase in the initial acceleration withdrawal value, the primary dendrite arm spacing in the stable growth zone decreases but the secondary dendrite arms are hardly affected.

(3) By growth velocity transition from higher one to lower one, the primary dendrite spacing and constitutional segregation can be reduced, and vice versa. A proper transition in the process 
parameters early in the formation of the dendritic microstructure might result in an improved product.

(4) Melt superheat treatment before solidification will stabilize solidification interface and refine primary dendrite significantly. The secondary dendrite spacing seems not sensitive to the melt superheat treatment.

\section{Acknowledgments}

Financial supports from National Major Research Plan on Basic Research (No.2006CB605202) and from National Natural Science Foundation of China (No. 50771081) are greatly acknowledged.

\section{References}

1. L. Li, and R. A. Overfelt, "Influence of directional solidification variables on the cellular and primary dendrite arm spacings of PWA1484,"J. Mater. Sci., 37 (2002) , $3521-3532$

2. A. Kermanpur, N. Varahraam, E. Engilehei, M Mohammadzadeh, and P. Davami. "Directional solidification of Ni base superalloy IN738LC to improve creep properties," Mater. Sci. Techn., 16 (2000), 579-586.

3. A. J. Elliott, S. Tin, W. T. King, S.-C. Huang, M. F. X. Gigliotti, and T. M. Pollock. "Directional Solidification of Large Superalloy Castings with Radiation and LiquidMetal Cooling: A Comparative Assessement," Metall. Mater. Trans. A, 35A (2004), 3221-3231.

4. A. Wagner, B. A. Shollock, and M. McLean. "Grain structure development in directional solidification of nickel-base superalloys," Mater. Sci. Eng., A 374 A (2004), 270-279.

5. S. H. Han, and R. Trivedi. "Primary spacing selection in directionally solidified alloys," Acta Metall. 42 (1994), 2541.

6. Huang Weidong, Geng Xingguo, and Zhou Yaohe. "Primary spacing selection of constrained dendritic growth," J. Cryst. Grow., 134 (1993), 105-115.

7. G. L. Ding, W. D. Huang, X. Huang, X. Lin, and Y. H. Zhou. "On primary dendritic spacing during unidirectional solidification," Acta Metall., 44 (1996), 3705-2709.

8. S.-Z. Lu, and J. D. Hunt. "A numerical analysis of dendritic and cellular array growth: the spacing adjustment mechanisms," J. Cryst. Growth, 123 (1992), 17-34.

9. J. A. Warren, and J. S. Langer. "Prediction of Dendritic Spacings in a Directional Solidification Experiment," Phys .Rev. E, 47 (1993), 2702-2712.

10. L. Liu, B. L. Zhen, A. Banerji, W. Reif, and F. Sommer. "Effect of melt homogenization temperature on the cast structures of IN 738 LC superalloy," Scripta Metall. Mater., 30 (1994), 593-598.

11. F. L. Yin, X.F. Sun, J.G. Li, H.R. Guan, and Z.Q. Hu. "Effects of melt treatment on the cast structure of M963 superalloy," Scripta Materialia, 48 (2003), 425-429.

12. G. K. Bouse, and J. R. Mihalisin. "Metallurgy of investment cast superalloy component," Superalloys,
Supercomposites and Superceramics, ed. J. K. Tien, and T. Caulfield (London: Academic Press, 1989), 99-148

13. Taiwen Huang, Lin Liu, Min Qu, Jun Zhang, and Hengzhi $\mathrm{Fu}$. "High thermal gradient directional solidification and its application in the processing of Nickel-based superalloys", submitted to Intern J Mater Res.

14. R. Mehrabian. "Relationship of heat flow to structure in rapid solidification processing," Rapid Solidification Processing: Principles and Technologies (Proceedings of the Intern. Conf. on Rapid Solidification processing Nov.13-16, 1977, Ruston, Virginia), ed. R. Mahrabian, B. H. Kear, and M. Cohen (Baton Rouge: Claitor's Pub. Division, 1977), 9-27.

15. H. Biloni, and W. J. Boettinger. "Solidification," Physical Metallurgy: $4^{\text {th }}$ revised and enhanced edition, ed. R. W. Cahn and P. Haasen (Amsterdam: Elsevier Science BV, 1996), 670-842.

16. J.S. Langer, and H. Müller-Krumbhaar. "Theory of dendritic growth - I. Elements of a stability analysis," Acta Metall., 26 (1978), 1681-1687.

17. W. Kurz, and D.J. Fisher. "Dendrite growth at the limit of stability: tip radius and spacing," Acta Metall., 29 (1981), 11-20

18. J. D. Hunt, and S.-Z. Lu. "Numerical Modeling of Cellular/Dendritic Array Growth:Spacing and Structure Predictions, "Metall. Mater. Trans. A, 27(3) (1996), 611622.

19. W. Wang, P. D. Lee, and M. McLean. "A model of solidification microstructures in nickel-based superalloys: predicting primary dendrite spacing selection," Acta Materialia, 51 (2003), 2971-2987.

20. F. S. Yin, X. F. Sun, H. R. Guan, and Z. Q. Hu. "Effect of thermal history on the liquid structure of a cast nickel-base superalloy M963," Journal of Alloys and Compounds, 364 (2004), 225-228. 